\title{
Nested case-control study of lung cancer in four Chinese tin mines
}

\section{W Chen, J Chen}

See end of article for authors' affiliations

\section{Correspondence to:} Dr W Chen, Institute of Hygiene and Occupational Medicine, Medical School, University of Essen, Hufeland Strasse 55 D-45122 Essen, Germany; weihong.chen@uni-essen.de

Accepted 27 July 2001

\begin{abstract}
Objectives: To evaluate the relation between occupational dust exposure and lung cancer in tin mines. This is an update of a previous study of miners with high exposure to dust at four tin mines in southern China.

Methods: A nested case-control study of 130 male lung cancer cases and 627 controls was initiated from a cohort study of 7855 subjects employed at least 1 year between 1972 and 1974 in four tin mines in China. Three of the tin mines were in Dachang and one was in Limu. Cumulative total exposure to dust and cumulative exposure to arsenic were calculated for each person based on industrial hygiene records. Measurements of arsenic, polycyclic aromatic hydrocarbons (PAHs), and radon in the work sites were also evaluated. Odds ratios (ORs), standard statistic analysis and logistic regression were used for analyses.

Results: Increased risk of lung cancer was related to cumulative exposure to dust, duration of exposure, cumulative exposure to arsenic, and tobacco smoking. The risk ratios for low, medium, and high cumulative exposure to dust were 2.1 (95\% confidence interval $(95 \% \mathrm{CI}) 1.1$ to 3.8$), 1.7(95 \%$ $\mathrm{Cl} 0.9$ to 3.1$)$, and $2.8(95 \% \mathrm{Cl} 1.6$ to 5.0$)$ respectively after adjustment for smoking. The risk for lung cancer among workers with short, medium, and long exposure to dust were $1.9(95 \% \mathrm{Cl} 1.0$ to 3.5$)$, $2.3(95 \% \mathrm{Cl} 1.3$ to 4.1$)$, and $2.3(95 \% \mathrm{Cl} 1.2$ to 4.2$)$ respectively after adjusting for smoking. Several sets of risk factors for lung cancer were compared, and the best predictive model included tobacco smoking $(\mathrm{OR}=1.6,95 \% \mathrm{Cl} 1.1$ to 2.4 ) and cumulative exposure to arsenic (ORs for different groups from low to high exposure were $2.1(95 \% \mathrm{Cl} 1.1$ to 3.9$) ; 2.1(95 \% \mathrm{Cl} 1.1$ to 3.9$) ; 1.8(95 \% \mathrm{Cl} 1.0$ to 3.6); and $3.6(95 \% \mathrm{Cl} 1.85$ to 7.3$))$. No excess of lung cancer was found among silicotic subjects in the Limu tin mine although there was a high prevelance of silicosis. Exposures to radon were low in the four tin mines and no carcinogenic PAHs were detected.

Conclusions: These findings provide little support for the hypothesis that respirable crystalline silica induces lung cancer. Ore dust in work sites acts as a carrier, the exposure to arsenic and tobacco smoking play a more important part in carcinogenesis of lung cancer in tin miners. Silicosis seems not to be related to the increased risk of lung cancer.
\end{abstract}

$\mathrm{T}$ he association between crystalline silica and lung cancer has been the subject of extensive discussion in recent years. In 1997, an International Agency for Research on Cancer (IARC) working group reviewed this subject and concluded that there was sufficient evidence in humans for the carcinogenicity of inhaled crystalline silica in the form of quartz or cristobalite from occupational sources. ${ }^{1}$ However, in their overall evaluation, the working group also noted that carcinogenicity in humans was not detected in all industrial circumstances. For the studies among ore miners who were potentially exposed to silica dust, consistent evidence for a relation between silica and lung cancer was not found. Also, confounders-such as other known occupational respiratory carcinogens-were not taken into account in most of these studies.

As ore mines, tin mines were the subject in several studies. Hodgson and Jones ${ }^{2}$ followed up a cohort of 3010 miners who worked between 1941 and 1984 in two tin ore mines in the United Kingdom. They found that mortality from lung cancer was significantly increased ( 105 observed, standardised mortality ratio (SMR) $1.58,95 \%$ CI 1.29 to 1.91 ) and that there was a strong dose-response relation with duration of exposure underground. Smoking and radon daughters (about 10 working level months) were considered to be the main risk factors for lung cancer in their study. High mortality of lung cancer was also reported among southern Chinese tin miners. ${ }^{3}{ }^{4} \mathrm{Fu}$ et $a l^{5}$ conducted a case-control study in one Chinese tin mine in the Dachang area and showed a significant correlation between lung cancer and years of underground exposure to dust. The smoking adjusted odds ratio (OR) for lung cancer was 1.05 (95\% CI 1.03 to 1.07), but they did not consider concomitant exposure to arsenic in that mine.

In 1992, one cohort study (1972-89) conducted by Chen et $a l^{6}$ including 7855 miners in four tin mines in southern China confirmed that the mortality from lung cancer was $189.25 \times 10^{-5}$, higher than the national mortality from lung cancer among city residents in China (89 observed, SMR 1.98, $95 \%$ CI 1.59 to 2.43 ). The mortality from lung cancer in miners with high exposure to dust was 2.2 (95\% CI 1.3 to 3.6 ) compared with miners with low or no exposure. From this cohort, Mclaughlin et al $7^{7}$ developed one nested case-control study which included tin mines, tungsten mines, copper/iron mines, and pottery factories. Their results supported an OR from lung cancer significantly related to exposure to dust and showed that exposure to arsenic confounded the doseresponse relation between exposure to crystalline silica and risk of lung cancer in tin mines. In their study, the mean age of the tin miners was only 50.4 at the end of 1989. Since then new subjects with lung cancer have been diagnosed. The present study followed up the previous cohort in four tin mines to the end of 1994 and initiated a nested case-control

Abbreviations: PAHs, polycyclic aromatic hydrocarbons; SMR, standardised mortality ratio; OR, odds ratio; CTD, cumulative total dust 


\section{Main messages}

- There was a positive exposure-response relation between exposure to dust and risk for lung cancer.

- There was no excess of lung cancer among silicotic patientss.

- There was a strong exposure-response relatjon between exposure to arsenic and risk for lung cancer.

\section{Policy implications}

- An exposure limit for exposure to dust with high arsenic contents should be considered.

- More information for evaluating risk of lung cancer and exposure to crystalline silica is needed.

study of lung cancer for analysis. Besides detailed cumulative total dust, exposure concentrations for individual miners were calculated, and historical estimates of exposure to arsenic were supplied in this study. All four tin mines are underground, with known occupational carcinogens including crystalline silica, arsenic, and radon. The objectives of this study are to verify previous findings and to clarify the role of crystalline silica and arsenic in the high mortality of lung cancer in these tin mines.

\section{MATERIALS AND METHODS}

\section{Research subjects}

This study compared four tin mines in Guangxi province in southern China, three tin mines in Dachang and one in Limu. The Dachang tin mines here are not the same as the Dachang tin mine in the study be Fu et al. ${ }^{5}$ All 7855 employees who had worked for at least 1 year between 1 January 1972 and 31 December 1974 in any of these four tin mines were selected to the cohort. The cohort was followed up to the end of 1994. All subjects who died of primary lung cancer were selected as cases. Two women cases were excluded from the analysis to avoid the influence of sex. These cases were matched to about five controls, based on age (decade of birth), sex, and mine. Controls who died at an age younger than the age at diagnosis of corresponding cases were excluded from analysis. Exposure and medical data were obtained from personal and medical examination records in each mine. A questionnaire was also administered to the study subject or a member of his family to obtain information on demographic factors, including medical history and tobacco smoking. Amount of tobacco smoking was expressed as packs of cigarettes/day $\times y$ years (pack-years) smoked. One pack was considered to consist of 20 cigarettes and the smoking of $50 \mathrm{~g}$ tobacco to be equivalent to three packs of cigarette.

\section{Ascertainment of lung cancer}

All subjects in the cohort were traced for vital status and cause of death to the end of 1994. For the cases who died of primary lung cancer, their diagnostic information such as biopsy results were reconfirmed through medical records in local or regional hospitals. A panel of professional radiologists reviewed all chest $x$ ray films of the cases of lung cancer for this study.

\section{Data on silicosis}

Chest radiographs for each cohort member were kept by hygienists in all four tin mines. Silicosis was defined as diagnosed by at least two of three radiologists in a panel who were using the 1986 Chinese pneumoconiosis radiographic diagnostic criteria as previously described. ${ }^{8}$ The Chinese stage I, II, and III were found to agree closely with ILO profusion category 1,2 , and 3, respectively.

\section{Occupational exposure data}

Industrial hygienists have regularly been measuring and recording environmental exposure to airborne total dust and percentage of silica for miners in the four tin mines since 1950s. The Chinese total dust monitoring scheme is based on a gravimetric method and uses a battery operated sampler which collects total airborne dust directly onto an exposed preweighed filter. The unit was usually placed near the workers when at work. Sampling at a flow rate of $25 \mathrm{l} / \mathrm{min}$, the sampler was typically operated for 15 to 20 minutes when the observed task was in progress. After sampling, the filters were placed in glass tubes and returned to the laboratory where they were weighed to determine the total airborne dust concentration.?

All available monitoring data were used to create a job title/ calendar year exposure matrix. For missing data on years or job titles, consensus estimations were made by industrial hygiene experts, public health doctors, safety engineers, samplers, and local supervisors based on the history of control measures and major changes in technical processes in the mines, and on comparisons with previous and subsequent years at this job title or the same year of other job titles. The previous job title/calendar year exposure matrix ${ }^{10}$ was modified for this study.

Work history (job titles and years) for every subject was abstracted from employment records in files of the mining companies. These records include job titles and calendar working year for the full duration of employment of the miners. The cumulative exposure to total dust was calculated for every subject by combining the exposure matrix and work history, with the following equation:

Cumulative exposure to total dust $\left(\mathrm{mg} / \mathrm{m}^{3}\right.$-year $)=\sum_{\mathrm{i}=1}^{\mathrm{n}}(\mathrm{Ci} \times \mathrm{Ti})$

Where: $\mathrm{Ci}=$ total dust concentration for the job and employment period obtained from the job-exposure matrix; $\mathrm{Ti}=$ duration of employment (years) of subject for the job (i) from work history, it was adjusted by the number of hours worked/day, one year in dust is defined as 8 hours/day and 270 days/year.

Respirable fraction of total dust was estimated to be $25 \% \pm 4 \%$ and respirable crystalline silica concentration was estimated to be $3.6 \% \pm 0.8 \%$ of the total dust concentration. ${ }^{11}{ }^{12}$ The conversion factors among different job titles in tin mines were not significantly different.

Airborne arsenic concentration before 1988 was estimated as the product of arsenic content of dust multiplied by the total dust concentration in the work sites. Direct airborne arsenic concentration was measured after 1988. Cumulative exposure to arsenic for individual miners was estimated by combined arsenic concentration and work history, such as cumulative exposure to total dust.

Confounding exposures including arsenic, polycyclic aromatic hydrocarbons (PAHs), radon, cadmium, etc, were only measured on work sites after $1988 .{ }^{9}$

\section{Statistical analysis}

The Mantel-Haenszel OR was used to measure the association between lung cancer and various hazards or risk factors in this analysis. A 95\% confidence interval (95\% CI) for the OR was calculated by Miettinen's test based method. The stratified analysis method was used to adjust for the effect of smoking. Statistical analyses were performed with the statistical analysis software (SAS). The $\chi^{2}$ values were calculated by SAS program PROC FREQ. The SAS program PROC CATMOD procedure was used to perform unconditional logistic regression models and to estimate the OR as a surrogate for the relative risk.

\section{RESULTS}

A total of 7855 miners were identified in our cohort. There were 5322 miners (male 4443 and female 879) from Dachang 
Table 1 Age distribution of miners in the cohort to the end of 1994

\begin{tabular}{|c|c|c|c|c|c|c|}
\hline & \multicolumn{2}{|l|}{ Male } & \multicolumn{2}{|c|}{ Female } & \multicolumn{2}{|l|}{ Total } \\
\hline & $\mathrm{n}$ & Age (mean (SD)) & $\mathrm{n}$ & Age (mean (SD)) & $n$ & Age (mean (SD)) \\
\hline Still working & 2674 & $47.6(5.4)$ & 408 & $45.7(5.3)$ & 3082 & $47.3(5.4)$ \\
\hline Left tin mines & 804 & $51.4(7.9)$ & 263 & $51.4(7.4)$ & 1067 & $51.4(7.8)$ \\
\hline Retired & 2085 & $63.9(7.3)$ & 587 & $59.2(5.5)$ & 2672 & $62.9(7.2)$ \\
\hline Dead & 981 & $58.5(12.3)$ & 53 & 49.3 (1 1.0$)$ & 1034 & $58.0(12.4)$ \\
\hline
\end{tabular}

Table 2 Characteristics of workers with lung cancer and controls

\begin{tabular}{lll}
\hline Characteristic & $\begin{array}{l}\text { Lung cancer cases (mean } \\
\text { (SD)) }\end{array}$ & $\begin{array}{l}\text { Controls (mean } \\
\text { (SD)) }\end{array}$ \\
\hline Subjects (n) & 130 & 627 \\
Year of birth & $1925.0(7.4)$ & $1925.5(8.1)$ \\
Year of entering tin mine & $1951.4(6.2)$ & $1952.7(6.5)$ \\
Age at entering tin mine & $26.4(6.9)$ & $27.2(7.1)$ \\
Subjects with exposure to dust (n) & 112 & 462 \\
Cumulative exposure to total dust (mg/m ${ }^{3}$-y) & $112.4(92.9)$ & $98.6(75.4)$ \\
Cumulative arsenic exposure & $525.5(581.8)$ & $439.4(469.1)$ \\
Duration of exposure & $14.4(8.4)$ & $14.4(8.6)$ \\
Smokers (n) & 115 & 517 \\
Smoking (pack-years, only for smokers) & $39.0(20.0)$ & $35.4(21.2)$ \\
Smoking-years (only for smokers) & $33.9(10.0)$ & $32.8(10.7)$ \\
Age at onset of lung cancer (y) & $60.7(8.4)$ & \\
Latency period* & $30.3(7.9)$ & \\
\hline \multirow{2}{*}{ *Latency period is the duration from first work to the onset of lung cancer. }
\end{tabular}

Table 3 Respirable concentration of arsenic by exposure $\left(\mu \mathrm{g} / \mathrm{m}^{3}\right)$ in tin mines

\begin{tabular}{|c|c|c|c|c|c|c|}
\hline \multirow[b]{2}{*}{ Dust exposure } & \multicolumn{3}{|c|}{ Three tin mines in Dachang } & \multicolumn{3}{|c|}{ Limu tin mine } \\
\hline & Samples & Range & $\begin{array}{l}\text { Mean } \\
\text { concentration }\end{array}$ & Samples & Range & $\begin{array}{l}\text { Mean } \\
\text { concentration }\end{array}$ \\
\hline High & 14 & $1.9-38.3$ & 10.2 & 3 & $0.36-0.7$ & 0.5 \\
\hline Medium & 2 & $2.4-4.7$ & 3.5 & 1 & 1.16 & 1.2 \\
\hline Low & 2 & $1.0-4.9$ & 3.0 & 0 & - & - \\
\hline No & 9 & $0.1-2.7$ & 1.1 & 0 & - & - \\
\hline
\end{tabular}

and 2533 (male 2101 and female 432) from Limu. The mean age was 34.9 years when miners entered the cohort in 1974 and 54.1 years for survivors at the end of 1994 in the cohort (table 1). Among the cohort, 3082 miners were still working, 1067 had left tin mines, 2672 had retired, and 1034 miners had died. There were 91 miners ( $1.2 \%$ of whole cohort) considered lost to follow up after they left the tin mines. The mortality of the cohort was $603.8 \times 10^{-5}$ and cancer was the leading cause of death $(38.2 \%)$. Among various cancers, lung cancer $(33.4 \%)$ was the top cause for deaths. The SMR of lung cancer was 2.39 times greater than the Chinese national mortality.

One hundred and thirty men with lung cancer and 640 controls were identified. Thirteen controls were excluded because of a lack of complete work history. So in the final analysis, the number of controls were 627. One hundred and one cases of lung cancer and 489 controls who came from Dachang, and 29 cases of lung cancer and 138 control miners came from Limu. A detailed comparison of general characteristics and dust exposure between cases and controls is provided in table 2. Among 112 cases of lung cancer who had worked with dust exposure, 26 cases started exposure before 1950, 74 cases started exposed work in 1950-60, and only 11 cases started exposure after 1960. High percentages of tobacco smokers were found among cases $(88.5 \%)$ and controls $(82.5 \%)$ in the tin mines. Smoking more than 20 cigarettes a day was associated with a 1.6 (95\% CI 1.1 to 2.4$)$ increased risk of lung cancer.

The mean concentration of total dust in four tin mines was about $25 \mathrm{mg} / \mathrm{m}^{3}$ before the 1950s. The dust concentration has been progressively decreasing since 1960 because work practices with increased protection have been installed and used. The mean concentration of total dust gradually decreased to $4-8 \mathrm{mg} / \mathrm{m}^{3}$ in the $1960 \mathrm{~s}$, $3-6 \mathrm{mg} / \mathrm{m}^{3}$ in the $1970 \mathrm{~s}$ and $1-4 \mathrm{mg} / \mathrm{m}^{3}$ after 1980 . The dust concentration in the Limu tin mine was slightly higher than in the Dachang mines, but not significantly so. Crystalline silica dust concentration ranged between $20 \%$ and $40 \%$ in the four mines, the mean $\%$ of crystalline silica was 34.8\% in Dachang and 34.6\% in Limu. Other metals in the dust included inorganic arsenic, aluminum, lead, and cadmium. The mean arsenic content of dust measured in 1988 was $6.03 \%$ in the Dachang tin mines and $0.46 \%$ in Limu. The respirable arsenic concentrations at different concentrations of dust are summarised in table 3. High respirable arsenic concentrations were found in Dachang, but not in the Limu tin mine. The mean concentration of underground PAHs was $372.9 \mu \mathrm{g} / \mathrm{m}^{3}$ in Dachang and $7.6 \mu \mathrm{g} / \mathrm{m}^{3}$ in Limu, but carcinogenic PAHs were not detected in all mines. The exposure concentration of radon was low in all mines, the mean exposure was 0.02 working level months/year in Dachang and 0.01 working level months/year in the Limu tin mine, 
Table 4 Odds ratios $(95 \% \mathrm{Cl})$ for lung cancer among tin miners by cumulative dust exposure and duration of exposure*

\begin{tabular}{|c|c|c|c|c|c|c|c|c|c|}
\hline & \multicolumn{3}{|c|}{ Three tin mines in Dachang } & \multicolumn{3}{|c|}{ Limu tin mine } & \multicolumn{3}{|l|}{ Total } \\
\hline & Cases & Controls & OR $(95 \% \mathrm{Cl})$ & Cases & Controls & OR $(95 \% \mathrm{CI})$ & Cases & Controls & OR $(95 \% \mathrm{CI})$ \\
\hline \multicolumn{10}{|c|}{ Cumulative total dust concentration $\left(\mathrm{mg} / \mathrm{m}^{3}-\mathrm{y}\right)$ : } \\
\hline No exposure & 16 & 146 & $1.0(-)$ & 2 & 19 & $1.0(-)$ & 18 & 165 & $1.0(-)$ \\
\hline Low $(<50)$ & 27 & 119 & $2.0(1.0$ to 4.0$)$ & 6 & 26 & $2.1(0.4-10.2)$ & 33 & 145 & $2.1(1.1-3.8)$ \\
\hline Medium (50-1 19.9) & 23 & 119 & $1.7(0.8$ to 3.5$)$ & 8 & 44 & $1.5(0.3$ to 8.1$)$ & 31 & 163 & $1.7(0.9$ to 3.1$)$ \\
\hline High $(\geqslant 120)$ & 35 & 105 & $3.0(1.6$ to 5.8$)$ & 13 & 49 & $2.4(0.6$ to 10.2$)$ & 48 & 154 & 2.8 (1.6 to 5.0$)$ \\
\hline $\mathrm{p}$ Value for trend $\dagger$ & & \multicolumn{2}{|c|}{$\chi^{2}=12.40 p=0.006$} & \multicolumn{3}{|c|}{$\chi^{2}=1.65 p=0.649$} & & \multicolumn{2}{|c|}{$\chi^{2}=13.50 p=0.004$} \\
\hline \multicolumn{10}{|l|}{ Duration of exposure: } \\
\hline No & 16 & 146 & $1.0(-)$ & 2 & 19 & $1.0(-)$ & 18 & 165 & $1.0(-)$ \\
\hline $0-9.9$ & 28 & 133 & $1.8(1.0$ to 3.5$)$ & 8 & 31 & $2.2(0.4$ to 11.3$)$ & 36 & 164 & 1.9 (1.0 to 3.5$)$ \\
\hline $10-19.9$ & 35 & 125 & $2.5(1.3$ to 4.1$)$ & 11 & 55 & $1.9(0.4$ to 8.3$)$ & 46 & 180 & $2.3(1.3$ to 4.1$)$ \\
\hline$\geqslant 20$ & 22 & 85 & 2.3 (1.2 to 4.2$)$ & 8 & 33 & $2.0(0.4$ to 9.4$)$ & 30 & 118 & $2.3(1.2$ to 4.2$)$ \\
\hline $\mathrm{p}$ Value for trend $\dagger$ & \multicolumn{3}{|c|}{$\chi^{2}=9.44 p=0.024$} & \multicolumn{3}{|c|}{$\chi^{2}=1.32 p=0.726$} & \multicolumn{3}{|c|}{$\chi^{2}=9.63 p=0.022$} \\
\hline
\end{tabular}

${ }^{*}$ Adjusted for tobacco smoking; †two sided $p$ value.

Table 5 Smoking adjusted odds ratio for lung cancer by cross categories of cumulative exposure to dust and cumulative exposure to arsenic

\begin{tabular}{|c|c|c|c|c|c|c|c|c|c|c|c|c|c|c|c|}
\hline \multirow{3}{*}{$\begin{array}{l}\text { Cumulative } \\
\text { exposure to } \\
\text { arsenic } \\
\left(\mu \mathrm{g} / \mathrm{m}^{3} \text {-year }\right)\end{array}$} & \multicolumn{15}{|c|}{ Cumulative exposure to total dust $\left(\mathrm{mg} / \mathrm{m}^{3}\right.$-year) } \\
\hline & \multicolumn{3}{|l|}{ No } & \multicolumn{3}{|c|}{ Low $(<50)$} & \multicolumn{3}{|c|}{ Medium (50-119.9) } & \multicolumn{3}{|c|}{ High $(>120)$} & \multicolumn{3}{|l|}{ Total } \\
\hline & Cases & Controls & $\begin{array}{l}\text { OR } \\
(95 \% \mathrm{Cl})\end{array}$ & Cases & Controls & $\begin{array}{l}\text { OR } \\
(95 \% \mathrm{Cl})\end{array}$ & Case & Controls & $\begin{array}{l}\text { OR } \\
(95 \% \mathrm{Cl})\end{array}$ & Case & Controls & $\begin{array}{l}\text { OR } \\
(95 \% \mathrm{Cl})\end{array}$ & Cases & S Controls & $\begin{array}{l}\text { OR } \\
(95 \% \mathrm{Cl})\end{array}$ \\
\hline No exposure & 18 & 165 & $1.0(-)$ & 0 & 0 & & 0 & 0 & & 0 & 0 & & 18 & 165 & $1.0(-)$ \\
\hline$<100$ & 0 & 0 & & 15 & 65 & $\begin{array}{l}2.1 \\
(1.0 \text { to } 4.4)\end{array}$ & 8 & 44 & $\begin{array}{l}1.7 \\
(0.7 \text { to } 4.1)\end{array}$ & 10 & 41 & $\begin{array}{l}2.2 \\
(0.9 \text { to } 5.0)\end{array}$ & 33 & 150 & $\begin{array}{l}2.0 \\
(1.1 \text { to } 3.7)\end{array}$ \\
\hline $100-499.9$ & 0 & 0 & & 18 & 80 & $\begin{array}{l}2.0 \\
(1.0 \text { to } 4.1)\end{array}$ & 14 & 66 & $\begin{array}{l}1.9 \\
(0.9 \text { to } 4.0)\end{array}$ & 3 & 8 & $\begin{array}{l}3.4 \\
(0.9 \text { to } 12.6)\end{array}$ & 35 & 154 & $\begin{array}{l}2.0 \\
(1.0 \text { to } 3.7)\end{array}$ \\
\hline 500-999.9 & 0 & 0 & & 0 & 0 & & 9 & 53 & $\begin{array}{l}1.5 \\
(0.6 \text { to } 3.5)\end{array}$ & 13 & 51 & $\begin{array}{l}2.3 \\
(1.0 \text { to } 4.9)\end{array}$ & 22 & 104 & $\begin{array}{l}1.9 \\
(1.0 \text { to } 3.7)\end{array}$ \\
\hline$\geqslant 1000$ & 0 & 0 & & 0 & 0 & & 0 & 0 & & 22 & 54 & $\begin{array}{l}3.5 \\
(1.8 \text { to } 7.0)\end{array}$ & 22 & 54 & $\begin{array}{l}3.5 \\
\text { (1.8 to } 7.0)\end{array}$ \\
\hline Total & 18 & 165 & $1.0(-)$ & 33 & 145 & $\begin{array}{l}2.1 \\
(1.1 \text { to } 3.8)\end{array}$ & 31 & 163 & $\begin{array}{l}1.7 \\
(0.5 \text { to } 3.1)\end{array}$ & 48 & 154 & $\begin{array}{l}2.8 \\
(1.6 \text { to } 5.0)\end{array}$ & & & \\
\hline
\end{tabular}

Table 6 Odds ratios for lung cancer among tin miners by stages of silicosis*

\begin{tabular}{|c|c|c|c|c|c|c|c|c|c|}
\hline \multirow[b]{2}{*}{ Silicosis } & \multicolumn{3}{|c|}{ Three tin mines in Dachang } & \multicolumn{3}{|c|}{ Limu tin mine } & \multicolumn{3}{|l|}{ Total } \\
\hline & Cases & Controls & OR $(95 \% \mathrm{Cl})$ & Cases & Controls & OR $(95 \% \mathrm{Cl})$ & Cases & Controls & OR $(95 \% \mathrm{Cl})$ \\
\hline No & 52 & 353 & $1.0(-)$ & 20 & 89 & $1.0(-)$ & 72 & 442 & $1.0(-)$ \\
\hline Stage I & 31 & 77 & 2.3 (1.3 to 3.9 ) & 2 & 24 & $0.4(0.1$ to 1.6$)$ & 33 & 101 & 1.9 (1.2 to 3.0$)$ \\
\hline Stage II & 15 & 45 & 2.2 (1.1 to 4.3$)$ & 6 & 19 & $1.4(0.5$ to 3.9$)$ & 21 & 64 & $2.0(1.1$ to 3.4$)$ \\
\hline Stage III & 3 & 14 & $1.4(0.4$ to 5.0$)$ & 1 & 6 & $0.7(0.1$ to 5.7$)$ & 4 & 20 & $1.2(0.4$ to 3.5$)$ \\
\hline $\begin{array}{l}\mathrm{p} \text { Value for } \\
\text { trendt }\end{array}$ & \multicolumn{3}{|c|}{$\chi^{2}=18.07 p=0.001$} & \multicolumn{3}{|c|}{$\chi^{2}=2.6 p=0.46 i$} & \multicolumn{3}{|c|}{$\chi^{2}=12.25 p=0.007$} \\
\hline
\end{tabular}

*Adjusted for cigarette smoking; †two sided $\mathrm{p}$ value.

both of them are below the occupational exposure limit in China. Asbestos was not detected.

The risks of lung cancer associated with cumulative exposure to total dust and duration of exposure after adjusting for tobacco smoking are given in table 4 . The mean values from low exposure to high exposure were $25.0 \mathrm{mg} / \mathrm{m}^{3}-\mathrm{y}, 82.5$ $\mathrm{mg} / \mathrm{m}^{3}-\mathrm{y}$, and $186.5 \mathrm{mg} / \mathrm{m}^{3}-\mathrm{y}$. The mean values from short to long duration of exposure were 5.8 years, 14.3 years, and 26.4 years. Compared with no exposure to dust, risk of lung cancer showed a significant increased trend with rising cumulative exposure to dust and extending duration of exposure. The risk of lung cancer among miners with exposure to dust was 2.2 (95\% CI 1.3 to 3.7) times higher than in those without exposure to dust. However, exposure to dust did not increase the risk of lung cancer in the Limu tin mine (OR 2.2; 95\% CI 0.5 to 9.6) when the Limu and Dachang mines were analyzed sepa- rately, although similar increased trends for the risk of lung cancer in both types of mines were found in three groups of exposure to dust.

Table 5 shows the risk ratios (95\% CIs) for lung cancer adjusted for smoking by cross categories of cumulative exposure to dust and cumulative exposure to arsenic. Significantly increased trends were found in the risk of lung cancer with increasing exposures to arsenic. The relative risk for subjects with low exposure to arsenic and high exposure to dust was 2.2 , close to the risk for subjects with low exposure to dust and medium exposure to arsenic (OR 2.0). High correlation $(r=0.82, \mathrm{p}=0.0001)$ was found between exposure to dust and exposure to arsenic, which prevented any adjustment for arsenic in the estimate of risk related to crystalline silica.

The percentage of silicosis in Dachang tin mine was $31 \%$ (185/590) and in Limu it was 35\% (58/167). Table 6 shows the 
Table 7 Relative risk $(95 \% \mathrm{Cl})$ for lung cancer from the logistic regression model

\begin{tabular}{|c|c|c|c|c|c|c|c|}
\hline & Model 1 & Model 2 & Model 3 & Model 4 & Model 5 & Model 6 & Model 7 \\
\hline \multicolumn{8}{|c|}{ Cumulative exposure to total dust $\left(\mathrm{mg} / \mathrm{m}^{3}-\mathrm{y}\right)$ : } \\
\hline $0.1-49.9$ & $2.1(1.1$ to 3.8$)$ & $2.0(1.1$ to 3.7$)$ & & & & & \\
\hline $50-119.9$ & $1.7(0.9$ to 3.1$)$ & $1.4(0.7$ to 2.8$)$ & & & & & \\
\hline$\geqslant 120$ & $2.8(1.6$ to 5.0$)$ & $2.1(1.1$ to 4.2$)$ & & & & & \\
\hline \multicolumn{8}{|c|}{ Duration of exposure: } \\
\hline $0.1-9.9$ & & & $2.0(1.1$ to 3.7$)$ & $1.7(0.9$ to 3.2$)$ & & & \\
\hline $10-19.9$ & & & $2.3(1.3$ to 4.0$)$ & $1.9(1.0$ to 3.5$)$ & & & \\
\hline$\geqslant 20$ & & & $2.3(1.2$ to 4.3$)$ & $1.9(1.0$ to 3.7$)$ & & & \\
\hline \multicolumn{8}{|c|}{ Cumulative exposure to arsenic $\left(\mu \mathrm{g} / \mathrm{m}^{3}-\mathrm{y}\right)$ : } \\
\hline $0.1-99.9$ & & & & & $2.1(1.1$ to 3.9$)$ & $1.8(0.9$ to 3.5$)$ & \\
\hline $100-499.9$ & & & & & $2.1(1.1$ to 3.9$)$ & $1.9(1.0$ to 3.5$)$ & \\
\hline $500-999.9$ & & & & & $1.8(1.0$ to 3.6$)$ & $1.4(0.7$ to 3.0$)$ & \\
\hline$\geqslant 1000$ & & & & & $3.6(1.8$ to 7.3$)$ & $2.6(1.2$ to 5.7$)$ & \\
\hline Tobacco smoking * & $1.6(1.1$ to 2.4$)$ & 1.5 (1.0 to 2.3$)$ & $1.6(1.1$ to 2.4$)$ & $1.5(1.0$ to 2.3$)$ & $1.6(1.1$ to 2.4$)$ & $1.6(1.0$ to 2.3$)$ & 1.5 (1.0 to 2.7$)$ \\
\hline Silicosis & & 1.5 (1.0 to 2.4$)$ & & 1.5 (1.0 to 2.3$)$ & & 1.5 (1.0 to 2.3 ) & 1.9 (1.3 to 2.7$)$ \\
\hline$p$ Value $^{\dagger}$ & $p=0.40$ & $\mathrm{p}=0.75$ & $p=0.81$ & $\mathrm{p}=0.19$ & $p=0.95$ & $p=0.35$ & $\mathrm{p}=0.42$ \\
\hline
\end{tabular}

*Tobacco smoking was divided into $\geqslant 20$ cigarettes/day and $<20$ cigarettes/day; $\uparrow p$ value for goodness of fit test, $p=1$ means completely fit, $p<0.1$ means can not fit.

risk for lung cancer by the categories of silicosis after controlling smoking. Few subjects were found in silicosis category 3 because most miners died for other complications before they developed to this stage. Significant excess of lung cancer among silicotic workers was found only in Dachang tin miners (OR 2.4, 95\% CI 1.6 to 3.8), and not in Limu tin miners (OR $0.8,95 \%$ CI 0.3 to 1.9 ).

Table 7 shows the relative risk (95\% CI) for lung cancer estimated from multivariate logistic regression models with different sets of risk factors. Tobacco smoking ( $\geqslant 20$ cigarette/ day $v<20$ cigarette/day) combined with cumulative exposure to dust, duration of exposure to dust, and cumulative exposure to arsenic were associated with the risk of lung cancer (models 1, 3, and 5). The likelihood ratio was used to test the goodness of fit for these models. When silicosis was included in the model, the goodness of fit of model 2 was higher than model 1 and model 7 , but silicosis did not significantly contribute to the risk of lung cancer $(p=0.08)$ in model 2 . The goodness of fit of model 4 and model 7 was lower than that of model 3, and the goodness of fit of model 6 and model 7 was lower than that of model 5 after silicosis was included. The duration of exposure did not show a significant trend in model 4 and silicosis did not significantly contribute to the risk of lung cancer in model $6(\mathrm{p}=0.08)$. Thus, the most significantly fitting model is model 5 , then model 3 , and models 1 and 7 .

\section{DISCUSSION}

Historically, the dust concentrations in the four tin mines in our study have been high and the percentage of crystalline silica in bulk dust was about $20 \%-40 \%$. The findings of this study confirm the results of previous study-strong increasing trends in risk of lung cancer with exposure to dust. This study also showed an increasing correlation between risk of lung cancer and duration of exposure to dust and cumulative exposure to arsenic. Tobacco smoking was another main factor related to the risk for lung cancer.

The carcinogenic risk of crystalline silica on humans in ore mines was assessed in several studies, but consistent evidence for a relation between crystalline silica and lung cancer was not found. The cohort studies conducted by McDonald et al, ${ }^{13}$ Steenland and Brown, ${ }^{14}$ Lawler et $a l,{ }^{15}$ and Kinlena and Willows ${ }^{16}$ provided limited support for the hypothesis that lung cancer is induced by crystalline silica. But contrary conclusions were drawn from the studies of Hnizdo and SluisCremer, ${ }^{17}$ Reid and Sluis-Cremer, ${ }^{18}$ Kusiak et al, ${ }^{19}$ Pham et al, ${ }^{20}$ and Amandus and Costello. ${ }^{21}$ They found increased standardised mortality ratios for lung cancer among miners exposed to crystalline silica dust. The results of case-control studies also provided different conclusion. Hnizdo et al supported the idea that the risk of lung cancer was associated with cumulative exposure to dust..$^{22}$ Mastangelo et al suggested an increased risk of lung cancer among silicotic workers. ${ }^{23}$ However, the studies by Samet et $a l^{24}$ and Heesel et $a l^{25}$ did not find significant dose-response effects for exposure to silica and lung cancer.

In our study, it is interesting that the relation between risk of lung cancer and cumulative exposure to dust or duration of exposure to dust was found only in the Dachang tin mines, not in Limu, despite the fact that dust concentrations and percentages of crystalline silica in dust were similar in all the tin mines. The fewer cases of lung cancer in the Limu tin mine may at least partly account for this difference because the trend of increasing ORs in three exposed groups of the Limu tin mine is not much different from that in the Dachang tin mines. However, the evidence of no excess of lung cancer among silicotic workers in the Limu tin mine cannot be explained only by smaller numbers. The number and prevalence of silicosis in the Limu tin mine (516 silicotic workers, 20.4\%) are higher than that in Dahang tin mines (418 silicotic workers, $7.9 \%$ ) in the cohort. That means that there are enough silicotic workers in the Limu tin mine, and the exposure concentration of dust in this tin mine is not lower than that in Dachang, because a clear exposureresponse relation for silicosis and cumulative exposure to dust was reported in our previous study in the same tin mines. ${ }^{26}$ Thus, the results from the Limu tin mine strongly suggest that silicosis is not a risk factor for lung cancer. This suggestion is also confirmed from the logistic model. When silicosis was included, it did not significantly contribute to the risk for lung cancer. As silicosis means high exposure to dust, the excess of lung cancer among silicotic workers should be attributed to the high cumulative exposure to dust.

The effects from other lung carcinogens, arsenic, PAHs, radon, and tobacco smoking were also evaluated in our study. Firstly, the carcinogenic PAHs were not detected in four tin mines, and radon exposures in all work sites were very low. Secondly, tobacco smoking is related to risk of lung cancer. It should be pointed that the percentages of smokers in both cases and controls were high $(88.5 \%$ in lung cancer cases and $82.5 \%$ in controls). The relation between exposure to dust or arsenic and risk of lung cancer was not changed after adjusting for smoking. Thirdly, arsenic as a positive carcinogenic agent was found to be associated with the risk for lung cancer. The positive dose-response trend was shown between cumulative exposure to arsenic and risk for lung cancer. Also, arsenic concentrations were high in Dachang and low in Limu. This would be another reason for lack of lung cancer among silicotic miners exposed to dust in the Limu tin mine. The 
study conducted by Taylor et $a l^{3}$ in tin mines in Yunnan province in China (high mortality from lung cancer was also found in this area) provided a conclusion consistent with ours. The concentrations of arsenic exposure in their study were close to (a littler higher than) those in our study, and their results suggested that the incidence of lung cancer is related to high arsenic concentration. They also suggested that duration of exposure to arsenic may be more important than intensity in the aetiology of lung cancer. Several other studies found high exposure to arsenic induced high incidence of lung cancer in smelter workers. ${ }^{27-30}$ But in these studies, airborne arsenic concentrations were higher than $50 \mu \mathrm{g} / \mathrm{m}^{3}$ and cumulative exposure to arsenic reached $750 \mu \mathrm{g} / \mathrm{m}^{3}$-year or more, higher than that in this study. Therefore, the carcinogenesis of crystalline silica cannot be excluded in our study, because a significant excess of lung cancer was found even in the lowest category of exposure to arsenic. The mean arsenic concentration was estimated to be about $3.7 \mu \mathrm{g} / \mathrm{m}^{3}$ and mean cumulative exposure to arsenic was $46.6 \mu \mathrm{g} / \mathrm{m}^{3}$-year in this category, too low to cause lung cancer because no excess of lung cancer was noted at the $10 \mu \mathrm{g} / \mathrm{m}^{3}$ concentration in the study by Enterline et al. ${ }^{31}$ High correlations between exposure to arsenic and exposure to dust or silica prevented us from going on to adjust any of these values during the analyses. Thus, crystalline silica was not the only carcinogenic factor in this study, ore particles work like carriers, arsenic stuck to ore particles seems to be more important for risk of lung cancer. Also, it should be noted that exposure assessment for confounding agents including arsenic, PAHs, and radon began in the 1980s. Total dust concentration greatly decreased from the 1950s to the 1980s, therefore the cumulative exposure to arsenic may have been underestimated or overestimated in the earlier years.

In summary, this study has shown some evidence to support the view that high exposure to dust may induce a high risk of lung cancer, and silicosis is not a direct risk for increased lung cancer. A strong dose-response relation was found between the risk of lung cancer and cumulative exposure to dust, cumulative exposure to arsenic, and duration of exposure to dust. High arsenic concentration in dust and smoking seem to play a more important part than crystalline silica in causing high mortality from lung cancer.

\section{ACKNOWLEDGEMENT}

We thank Dr Paul J A Borm (Medical Institute for Environmental Hygiene in Duesseldorf) and Professor Joachim Bruch (Institute for Hygiene and Occupational Medicine in University of Essen) for reviewing the manuscript and providing many valuable comments. We also thank Professor Chen Rongan at Tongji Medical College and industrial hygienists in the four tin mines for participating in this survey.

\section{Authors' affiliations}

W Chen, J Chen, Department of Labor Health and Occupational Diseases, Tongii Medical College, 13 Hang Kong Lu, Wuhan, Hubei, People's Republic of China

\section{REFERENCES}

1 International Agency for Research on Cancer. IARC monographs on the evaluation of carcinogenic risks to humans, Vol 68. Silica, some silicates, coal dust and para-aramide fibrils. Lyon: IARC; 1997:209-11.

2 Hodgson JT, Jones RD. Mortality of a cohort of tin miners 1941-86. Br J Ind Med 1990;47:665-76.
3 Taylor PR, Qiao YL, Schatzkin A, et al. Relation of arsenic exposure to lung cancer among tin miners in Yunnan Province, China. Br J Ind Med 1989;46:881-6

4 Yu Y, Huang M, Xu G. The occupational causes for high incidence of lung cancer among underground miners in Yunan tin mines. Chinese Journal of Industrial Hygiene and Occupational Diseases 1993;1 1:73-5.

5 Fu H, Gu X, Jin X, et al. Lung cancer among tin miners in southeast China: silica exposure, silicosis, and cigarette smoking. Am J Ind Med 1994;26:373-81

6 Chen J, McLaughlin JK, Zhang JY, et al. Mortality among dust-exposed Chinese mine and pottery workers. J Occup Med 1992:34:31 1-6.

7 McLaughlin JK, Chen JQ, Dosemeci M, et al. A nested case-control study of lung cancer among silica exposed workers in China. Br J Ind Med 1992;49: 167-71

8 Hodous TK, Chen R-A, Kinaley KB, et al. A comparison of pneumoconiosis interpretation between Chinese and American readers and classifications. Journal of Tongii Medical University 1991;11:225-9.

9 Wu Z, Hearl F, Peng K, et al. Current occupational exposure in Chinese iron and copper mines. Appl Occup Environ Hyg 1992;7:735-43.

10 Dosemeci $M$, Chen JQ, Hearl F, et al. Estimating historical exposure to silica among mine and pottery workers in the People's Republic of China. Am J Ind Med 1993:24:55-66.

11 Gao P, Chen BT, Hearl FJ, et al. Estimating factors to convert Chinese "total dust" measurements to ACGIH respirable concentrations in metal mines and pottery industries. Ann Occup Hyg 2000;44:251-7.

12 Zhuang Z, Hearl F, Chen W, et al. Estimating historical respirable crystalline silica exposure for Chinese pottery workers and iron/copper, tin, and tungsten miners. Ann Occup Hyg 2001;45:631-42.

13 McDonald JC, Gibbs GW, Liddell FD, et al. Mortality after long exposure to cummingtonite-grunerite. Am Rev Respir Dis 1978;118:271-7.

14 Steenland K, Brown D. Mortality study of gold miners exposed to silica and non-asbestiform amphibole minerals: an update with 14 more years of follow up. Am J Ind Med 1995;27:217-29.

15 Lawler A, Mandel J, Schuman L. Mortality study of Minnesota iron ore miners: premliminary results. In: Wagner WI, Rom WN, Merchant JA, eds. Health issue related to metal and nonmetallic mining. Boston: Butterworths: 1983.

16 Kinlen LJ, Willows AN. Decline in the lung cancer hazard: a prospective study of the mortality of iron ore miners in Cumbria. $\mathrm{Br} J$ Ind Med 1988;45:219-24.

17 Hnizdo E, Sluis-Cremer GK. Silica exposure, silicosis, and lung cancer: a mortality study of South African gold miners. Br J Ind Med 1991;48:53-60.

18 Reid PJ, Sluis-Cremer GK. Mortality of white South African gold miners. Occup Environ Med 1996;53:11-6.

19 Kusiak RA, Springer J, Ritchie AC, et al. Carcinoma of the lung in Ontario gold miners: possible aetiological factors. Br J Ind Med 1991;48:808-17.

20 Pham QT, Gaertner M, Mur JM, et al. Incidence of lung cancer among iron miners. Eur J Respir Dis 1983;64:534-40.

21 Amandus $\mathbf{H}$, Costello J. Silicosis and lung cancer in US metal miners. Arch Environ Health 1991:46:82-9.

22 Hnizdo E, Murray J, Klempman S. Lung cancer in relation to exposure to silica dust, silicosis and uranium production in South African gold miners. Thorax 1997;52:271-5

23 Mastrangelo G, Zambon P, Simonato L, et al. A case-referent study investigating the relationship between exposure to silica dust and lung cancer. Int Arch Occup Environ Health 1988;60:299-302.

24 Samet JM, Pathak DR, Morgan MV, et al. Silicosis and lung cancer risk in underground uranium miners. Health Phys 1994;66:450-3.

25 Hessel PA, Sluis-Cremer GK, Hnizdo E. Silica exposure, silicosis, and lung cancer: a necropsy study. Br J Ind Med 1990;47:4-9.

26 Chen W, Zhuang Z, Attfield MD, et al. Exposure to silica and silicosis among tin miners in China: exposure-response analyses and risk assessment. Occup Environ Med 2001;58:31-7.

27 Jarup L, Pershagen G. Arsenic exposure, smoking, and lung cancer in smelter workers: a case-control study. Am J Epidemiol 1991;134:545 51 .

28 Hertz-Picciotto I, Smith AH. Observations on the dose-response curve or arsenic exposure and lung cancer. Scand J Work Environ Health 1993;19(4):217-26.

29 Enterline PE, Marsh GM, Henderson V, et al. Mortality update of a cohort of US man made mineral fibre workers. Ann Occup Hyg $1987 ; 31: 625-56$

30 Enterline PE, Day R, Marsh GM. Cancers related to exposure to arsenic at a copper smelter. Occup Environ Med 1995;52:28-32.

31 Enterline PE, Marsh GM, Esmen NA, et al. Some effects of cigarette smoking, arsenic, and $\mathrm{SO}_{2}$ on mortality among US copper smelter workers. J Occup Med 1987;29:831-8. 